\title{
Analysis of neonatal cardiac function in infants with and without patent ductus arteriosus
}

Kathryn Broadhouse ${ }^{1,2}$, Anthony N Price ${ }^{1,2}$, Giuliana Durighel ${ }^{1}$, Anna Finnemore ${ }^{1,2}$, David J Cox ${ }^{1,2}$, AD Edwards ${ }^{1,2}$, Joseph V Hajnal ${ }^{1,2}$, Alan Groves ${ }^{1,2^{*}}$

From 16th Annual SCMR Scientific Sessions

San Francisco, CA, USA. 31 January - 3 February 2013

\section{Background}

Persistent PDA remains a common clinical presentation in preterm infants. We have already shown that high shunt volume increases $\mathrm{LVO}[1]$ and infants appear to have enlarged hearts (fig 1) but to what extent and their resultant function is yet unknown. The aim of this study was to quantify ventricular dimension and function in "healthy" neonates. Then compare PDA infants to this normative range to determine the impact of shunt volume.

\section{Methods}

Scans were performed at $3 \mathrm{~T}$ using pediatric and extremities coils. Infants were scanned with ear protection, routine monitoring and without sedation/anesthesia. Optimized 2D SSFP short axis 10-slice stacks[2] (resolution $=0.5 \times 0.5 \mathrm{~mm}$, slice $=4 \mathrm{~mm}$ ) were acquired. Segmentation and quantification was carried out using freely available software Segment[3], the AHA model was used for wall analysis. Description of shunt volume quantification is described

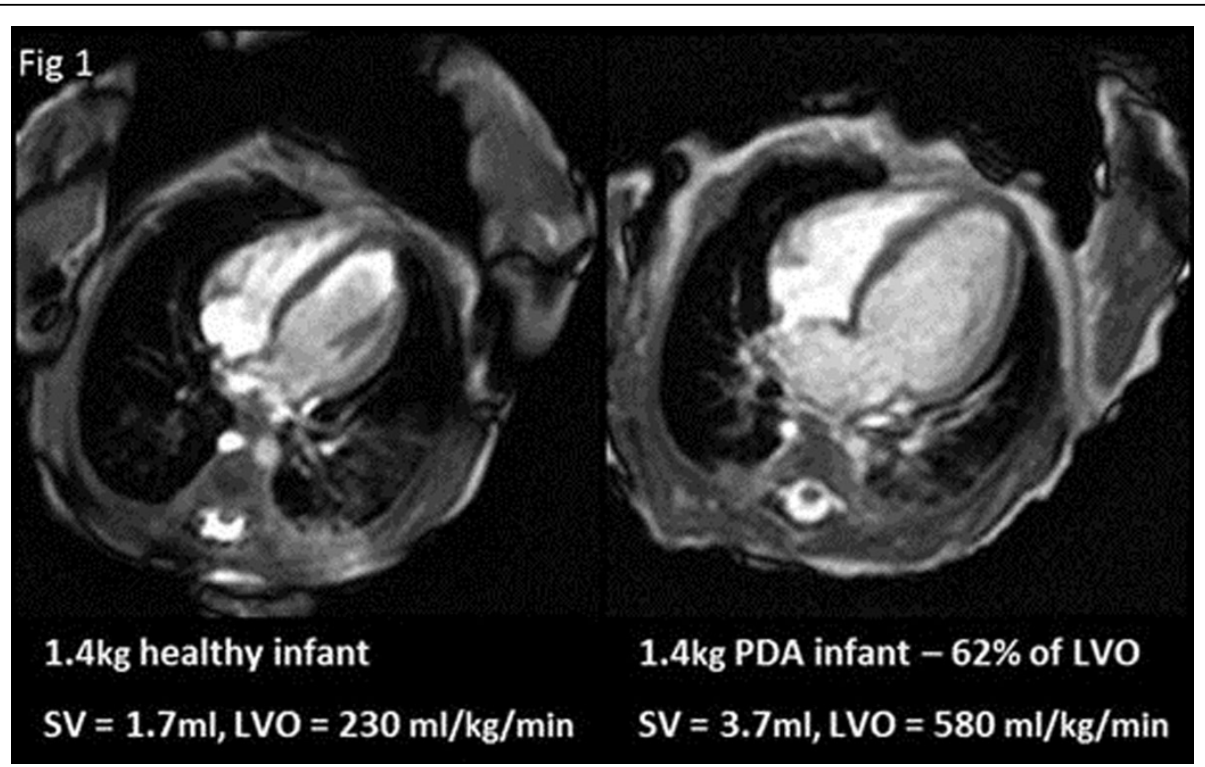

Figure 14 chamber view at end diastole in a 1.4kg control infant (left) and PDA (right) infant with a shunt volume of 62\% of LVO. 


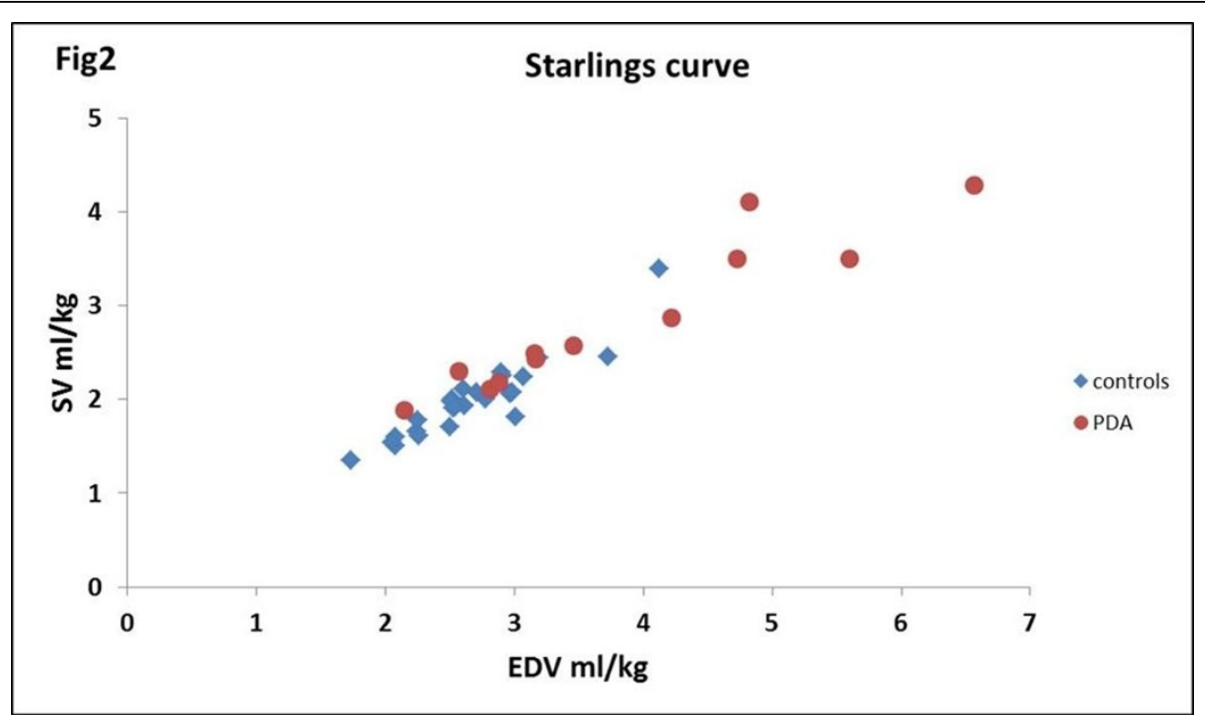

Figure 2 Population Starlings curve for controls and PDA infants.

previously [1]. The ventricular dimension parameters LVmass, end diastolic volume (EDV), wall thickness and ventricular function parameters of stroke volume (SV), $\mathrm{LVO}$, ejection fraction (EF), and fractional thickening (\% thick) were quantified for both "healthy" (control) and PDA infants. The 2 groups were compared using unpaired student $\mathrm{t}$-tests. Impact of shunt volume was analysed with multiple linear regression, $\mathrm{p}$-values $\leq 0.05$ being significant. Statistical analysis was carried out in Excel (Microsoft). Starlings curve was plotted to determine effect of PDA.

\section{Results}

27 control infants median(range) corrected-GA $34+4(28$ $+3-39+3)$ weeks, weight at scan $1730(790-3050)$ grams and 12 PDA infants (determined by echo prior to MRI) corrected-GA $29+5(27+3-36+1)$ weeks, weight at scan 1100(660-2400)grams were scanned. Shunt volume ranged from $7-74 \%$ of LVO[1]. T-tests showed significant difference in SV, EDV, ED wall thickness and LVmass between control and PDA infants when normalized by weight at scan. There was a significant association between shunt volume and increased LV mass when correcting for postnatal age and corrected-GA. However there was no significant difference in EF and \%thick between the two groups (p-value=0.6 and 0.75). None of the PDA infants were over the Starlings curve (fig 2).

\section{Conclusions}

Although LVO, EDV and LVmass are significantly increased in PDA infants, EF and \%thick are not. In addition none of the PDA infants are over the Starlings curve. This would suggest that function is maintained in these enlarged hearts.

\section{Funding}

MRC UK studentship.

\section{Author details}

${ }^{1}$ Imaging Sciences Department, MRC Clinical Sciences Centre, Imperial College, Hammersmith Hospital, London, UK. ${ }^{2}$ The Centre for the Developing Brain, Imaging Sciences \& Biomedical Engineering Division, St Thomas' Hospital, King's College, London, UK.

Published: 30 January 2013

\section{References}

1. Broadhouse $\mathrm{K}$, et al:. proc ISMRM 2011, 1195

2. Price AN, et al.: MRM 2012.

3. Heiberg $E$, et al:. BMC Medical Imaging 2010, 10:1.

doi:10.1186/1532-429X-15-S1-P289

Cite this article as: Broadhouse et al:: Analysis of neonatal cardiac

function in infants with and without patent ductus arteriosus. Journal of Cardiovascular Magnetic Resonance 2013 15(Suppl 1):P289.
Submit your next manuscript to BioMed Central and take full advantage of:

- Convenient online submission

- Thorough peer review

- No space constraints or color figure charges

- Immediate publication on acceptance

- Inclusion in PubMed, CAS, Scopus and Google Scholar

- Research which is freely available for redistribution

Submit your manuscript at www.biomedcentral.com/submit 